\title{
A scoping review of competencies for scientific editors of biomedical journals
}

\author{
James Galipeau ${ }^{1 *}$ (D), Virginia Barbour², Patricia Baskin ${ }^{3,13}$, Sally Bell-Syer ${ }^{4,14}$, Kelly Cobey ${ }^{1,15}$, Miranda Cumpston ${ }^{5,16}$, \\ Jon Deeks ${ }^{6}$, Paul Garner ${ }^{7}$, Harriet MacLehose ${ }^{8}$, Larissa Shamseer ${ }^{1,10}$, Sharon Straus ${ }^{9}$, Peter Tugwell ${ }^{1,10,17}$, \\ Elizabeth Wager ${ }^{11}$, Margaret Winker ${ }^{12}$ and David Moher ${ }^{1,10}$
}

\begin{abstract}
Background: Biomedical journals are the main route for disseminating the results of health-related research. Despite this, their editors operate largely without formal training or certification. To our knowledge, no body of literature systematically identifying core competencies for scientific editors of biomedical journals exists. Therefore, we aimed to conduct a scoping review to determine what is known on the competency requirements for scientific editors of biomedical journals.

Methods: We searched the MEDLINE ${ }^{\oplus}$, Cochrane Library, Embase ${ }^{\oplus}$, CINAHL, PsycINFO, and ERIC databases (from inception to November 2014) and conducted a grey literature search for research and non-research articles with competency-related statements (i.e. competencies, knowledge, skills, behaviors, and tasks) pertaining to the role of scientific editors of peer-reviewed health-related journals. We also conducted an environmental scan, searched the results of a previous environmental scan, and searched the websites of existing networks, major biomedical journal publishers, and organizations that offer resources for editors.
\end{abstract}

Results: A total of 225 full-text publications were included, 25 of which were research articles. We extracted a total of 1,566 statements possibly related to core competencies for scientific editors of biomedical journals from these publications. We then collated overlapping or duplicate statements which produced a list of 203 unique statements. Finally, we grouped these statements into seven emergent themes: (1) dealing with authors, (2) dealing with peer reviewers, (3) journal publishing, (4) journal promotion, (5) editing, (6) ethics and integrity, and (7) qualities and characteristics of editors.

Discussion: To our knowledge, this scoping review is the first attempt to systematically identify possible competencies of editors. Limitations are that (1) we may not have captured all aspects of a biomedical editor's work in our searches, (2) removing redundant and overlapping items may have led to the elimination of some nuances between items, (3) restricting to certain databases, and only French and English publications, may have excluded relevant publications, and (4) some statements may not necessarily be competencies.

Conclusion: This scoping review is the first step of a program to develop a minimum set of core competencies for scientific editors of biomedical journals which will be followed by a training needs assessment, a Delphi exercise, and a consensus meeting.

Keywords: Biomedical, Competencies, Journal, Scientific editor, Scoping review

\footnotetext{
* Correspondence: jgalipeau@ohri.ca

'Clinical Epidemiology Program, Ottawa Hospital Research Institute, Ottawa,

Canada

Full list of author information is available at the end of the article
} International License (http://creativecommons.org/licenses/by/4.0/), which permits unrestricted use, distribution, and reproduction in any medium, provided you give appropriate credit to the original author(s) and the source, provide a link to the Creative Commons license, and indicate if changes were made. The Creative Commons Public Domain Dedication waiver (http://creativecommons.org/publicdomain/zero/1.0/) applies to the data made available in this article, unless otherwise stated. 


\section{Background}

"...journals, some of which have reported research for many decades, are still not producing articles that are clear enough to really judge a study's conduct, quality, and importance-let alone to allow other researchers to reproduce it or build on it" [1].

Biomedical journals are the main route for disseminating the results of health-related research [2]. However, when examined more closely, the articles that journals publish are problematic; critical details are often missing or poorly reported, consequently reducing their quality, transparency, reproducibility, and usefulness for decision makers [3] - this is wasteful, diminishes scientific and fiscal value, and is unethical [4]. Authors and scientific journals share the majority of the responsibility for these shortcomings, as the former are accountable for the integrity of a study's conduct and the accuracy of reporting of the content within the manuscript, while the latter are accountable for decisions regarding its publication. On the side of journals, it is scientific editors (by which we mean editors, and ultimately the Editor-in-Chief, who are tasked with making decisions about the content and policies of journals) who are accountable for all material published in their journals. Readers have a right to expect these editors to implement all reasonable actions that could lead to best practices within their journals, as well as journals having processes in place to ensure the quality of the papers they publish.

Unlike many other professional groups, such as clinicians and healthcare professionals, many scientific editors of biomedical journals operate largely without formal training and universal certification is not yet a high priority [5]. Instead, editors generally are invited to serve in their role by publishers, based on their expertise and stature in the field, since such expertise is essential for evaluating research and stature is important for establishing the reputation of the journal and attracting submissions. However, such expertise does not guarantee that editors have the background or training necessary to carry out their roles and responsibilities. Editors may or may not be paid for their role and financial support for the editorial role often does not include travel or training funds. Most editors work part-time as they continue their academic responsibilities in research and/or clinical work, with time for completing editorial responsibilities - much less training - being at a premium. Researchers and peer reviewers similarly have no international standardized formal training or certification as to research conduct, reporting, and evaluation, making the editor's job even more demanding. This situation is highly problematic given that the consequences of deciding what gets published and the degree of quality that is acceptable impacts future research, decisions, and healthcare directly. Our view is that the lack of consistent training of editors reduces the value of the published literature, including its quality, transparency, and reproducibility, thereby reducing value for money to funders and the usability of research findings, ultimately degrading public trust in the research record [3]. However, we are unaware of any research that directly addresses this topic. Additionally, while the training of biomedical editors is an important mechanism to ensure the quality of the published literature, other important changes in tandem with this, including reexamining the training offered to peer-reviewers and training graduate students in study conduct, analysis, interpretation, and reporting, could also have a beneficial effect.

Some organizations, for example, the World Association of Medical Editors (WAME) [6] and the Committee on Publication Ethics (COPE) [7], provide rigorouslydeveloped resources for biomedical journal editors free of charge, including guidance on the role of the medical editor, editorial policies, and listservs on which editors' questions and issues are discussed. There are also individual websites and blogs, such as "Journalology" [8], that provide thoughtful commentary on current issues related to publication science. Several commercial groups offer short training courses for editors $[9,10]$. However, for any comprehensive editor training program to work effectively and be assimilated into practice, it must be based on what the broader biomedical editor community considers to be core competencies.

We are unaware of any body of literature systematically identifying core competencies for biomedical editors, nor any agreement on or attempt at a consensus process to determine what they should be. For the purposes of this research, we borrow from the literature on competency-based continuing professional development to define competence as "the array of abilities across multiple domains or aspects of [practitioner] performance in a certain context" [11]. We thus define core competencies as the essential knowledge, skills, and behaviors necessary for the practice of scientific editing of biomedical journals. We believe it is important to develop a set of core competencies so that training programs can then be developed and tailored with the intent that all editors meet some basic globally agreedupon standards. Other stakeholders, such as publishers (including medical associations who have their own journals), peer reviewers, and authors (researchers), also need to contribute to this effort. Herein, as a starting point, we report a scoping review of possible core competencies of scientific editors of biomedical journals.

\section{Objectives}

The objective of this scoping review was to conduct a systematic search of the literature on the competencies 
required for scientific editors of biomedical journals to effectively and efficiently produce transparently reported and correctly analyzed and interpreted publications. Our specific aim was to answer the research question: "What is known from the literature on the competency requirements of scientific editors of peer reviewed biomedical journals?" with the goal of summarizing the existing literature. The purpose of this scoping review is to inform the future development of a set of core competencies for scientific editors of biomedical journals, which we hypothesize will ultimately lead to improvements in the quality of the published literature.

\section{Methods}

The protocol for this project has previously been deposited in the University of Ottawa's Digital Repository (uOttawa Research) prior to beginning the screening phase [12]. Our methodological approach was guided by the Arksey and O'Malley Framework [13], as well as the additional suggestions to this framework made by Levac [14]. Specifically, we undertook the six-step process of: (1) identifying the research question; (2) identifying relevant studies; (3) study selection; (4) charting the data; (5) collating, summarizing, and reporting results; and (6) consultation.

\section{Search strategy}

We searched the MEDLINE ${ }^{\circ}$, Cochrane Library, Embase ${ }^{\circ}$, CINAHL, PsycINFO, and ERIC databases, all from inception to November 10th, 2014 (Additional file 1). The specific search strategies were created by a Health Sciences Librarian with expertise in scoping review searching. The MEDLINE strategy was developed with input from the project team, then peer reviewed by a second librarian not otherwise associated with the project using the PRESS standard [15]. We also conducted a grey literature search, which included hand searching the reference lists of included articles, as well as searching key journals, in particular JAMA from 1989, and BMJ, PLoS Medicine, European Science Editing, Annals of Internal Medicine, and $C M A J$ from 2004 onward to identify publications related to the Peer Review Congresses [16].

\section{Expanded scoping exercise}

Given that this scoping review is part of a larger program to develop core competencies for scientific editors of biomedical journals, in addition to seeking research literature, we also incorporated an expanded scoping exercise that included non-research-based (published and unpublished) materials to fill an expected gap in research on competencies of scientific editors of biomedical journals. This expectation was based on a previous systematic review [17], which found no comparative studies on training for scientific editors of biomedical journals, and an associated environmental scan that found only a few training opportunities for these editors [18]. Additionally, our anecdotal experience was that most descriptions of editor competencies are found in editorial-type publications (e.g. commentaries), job postings, and guidance documents (e.g. COPE Guidelines for Editors) - all of which would not generally be captured in a traditional scoping review of published research.

The expanded scoping exercise included (1) searching the databases from the search strategy and grey literature for non-research-based publications, (2) searching the results of an environmental scan from a previous related project $[17,18]$, (3) conducting a new environmental scan with additional search terms, and (4) searching the websites of existing networks (i.e. EQUATOR Network), major biomedical journal publishers (i.e. Wiley-Blackwell, Elsevier, BioMed Central, BMJ Publishing Group, Springer), and organizations that offer resources for editors (i.e. COPE, WAME, Council of Science Editors, European Association of Science Editors, and International Committee of Medical Journal Editors). For the database searches, the full-text of all potentially relevant documents were retrieved and independently reviewed for eligibility, in duplicate, by members of the team using a priori eligibility criteria. Disagreements between reviewers were resolved by consensus or by a third member of the research team. Both environmental scans employed the same methodology, which involved the use of the Google search engine to run a series of twoand three-word keyword searches (Additional file 1). For each set of search outcomes, the first 50 Google results were screened for relevant information. If any of the last 10 results contained useful information, another 10 results were screened. This process was continued until a set of 10 results with no relevant information was found [18].

\section{Study selection: inclusion criteria Population}

Articles with statements mentioning competencies, knowledge, skills, behaviors, and tasks (henceforth referred to as 'competency-related statements') pertaining to the role of scientific editors of peer-reviewed healthrelated journals (including Editors-in-Chief and associate/ academic editors, and full-time professional journal editors) were included. Articles related to all other types of editor not directly involved in evaluation, peer review, revision, and selection of content (e.g. managing editors, technical editors, copy editors) were excluded.

\section{Disciplines}

We adopted MEDLINE's journal selection criteria for our definition of health [19]. This definition includes journals that are "predominantly devoted to reporting original investigations in the biomedical and health 
sciences, including research in the basic sciences; clinical trials of therapeutic agents; effectiveness of diagnostic or therapeutic techniques; or studies relating to the behavioral, epidemiological, or educational aspects of medicine" [19]. This definition encompasses biomedical journals as well as those in the disciplines of psychology and education. For feasibility purposes, we did not include journals from the physical or natural sciences.

\section{Study designs}

The review included all study designs as well as editorials and commentaries. Economic evaluations and letters were excluded, as neither was expected to contribute useful data for the purposes of this scoping review. For feasibility purposes, we included articles written in English and French only. We did not include English or French abstracts of papers written in another language.

\section{Screening}

Following the execution of the search strategy, the identified records (titles and available abstracts) were collated in a Reference Manager [20] database for deduplication. The final unique record set of potentially eligible studies was exported to Internet-based software, DistillerSR (Evidence Partners, Ottawa, Canada), through which screening of records and data extraction were carried out. Each title and abstract was screened by two of four reviewers (LS, JG, JT (see Acknowledgements), and MG (see Acknowledgements)) using a 'liberal accelerated' method [21] (i.e. one reviewer screened each record and a second reviewer screened only excluded records, independently). The full-text of all remaining potentially eligible papers was then retrieved, uploaded into DistillerSR, and reviewed for eligibility, independently, by two members of the team (LS and JG) using a priori eligibility criteria. Disagreements between reviewers at this stage were resolved by consensus or by a third member of the research team.

\section{Charting the data}

A data extraction form was developed a priori to capture information on each document included in the review. It was piloted and refined based on feedback from the exercise. Three people (JG, KDC, LS) carried out data extraction in the following manner: data were extracted by one reviewer and a second reviewer conducted verification of the data for all records. Disagreements between reviewers were resolved by consensus. General study characteristics extracted for the database search were: first author name and contact information (of corresponding author), year of publication, institutional affiliation of first author, country, language of publication, study design, and funding source. For the environmental scans we extracted the URL, title of the document, language of publication, and who produced the document (affiliation). For all documents, we collected descriptions of any statements potentially relating to the competencies of scientific editors of biomedical journals, such as descriptions of particular skills, knowledge, attitudes, behaviors, tasks, and training.

\section{Collating, summarizing, and reporting the results}

In an effort to create a useful summary of the data for the next steps of our program to develop core competencies for scientific editors of biomedical journals, we combined the competency-related statements retrieved from all sources. First, two people (JG, KDC) classified all statements pertaining only to Editors-in-Chief into a single category, since these would be considered to be beyond the core competencies of scientific editors more generally. They then collated overlapping or duplicate statements to produce a list of unique statements. Finally, they grouped statements into emergent themes to make them more manageable for future use (e.g. in an upcoming Delphi exercise), and so that they would be understandable to readers. While some of the wording of particular statements was modified to assimilate overlapping statements, where statements were expressed as knowledge, skills, behaviors, or tasks that implied competencies, but not as competencies themselves, we did not edit or translate them to express competencies, in order to preserve the original intent. The relationships between behaviors, tasks, and competencies will be the subject of discussion and translation undertaken as part of the consensus meeting phase of this project.

\section{Results}

\section{Database search}

We screened 5,837 titles and abstracts, of which 360 were screened in full-text (Fig. 1). Of these, 206 were excluded, leaving 154 publications meeting the inclusion criteria. Twenty-five of these publications were research based (Table 1) and the remaining 136 were editorial in nature (Additional file 2).

\section{Charting the data \\ General characteristics}

Research-based publications A total of 18 publications from the database search presenting the results of research (subsequently termed 'research-based publications') were considered relevant to core competencies for scientific editors of biomedical journals, along with another seven articles found in the grey literature search (including six conference abstracts for which there appears to be no full text publication) (Table 1). None of these 25 articles had an outline or description of core competencies of scientific editors as an objective of the 


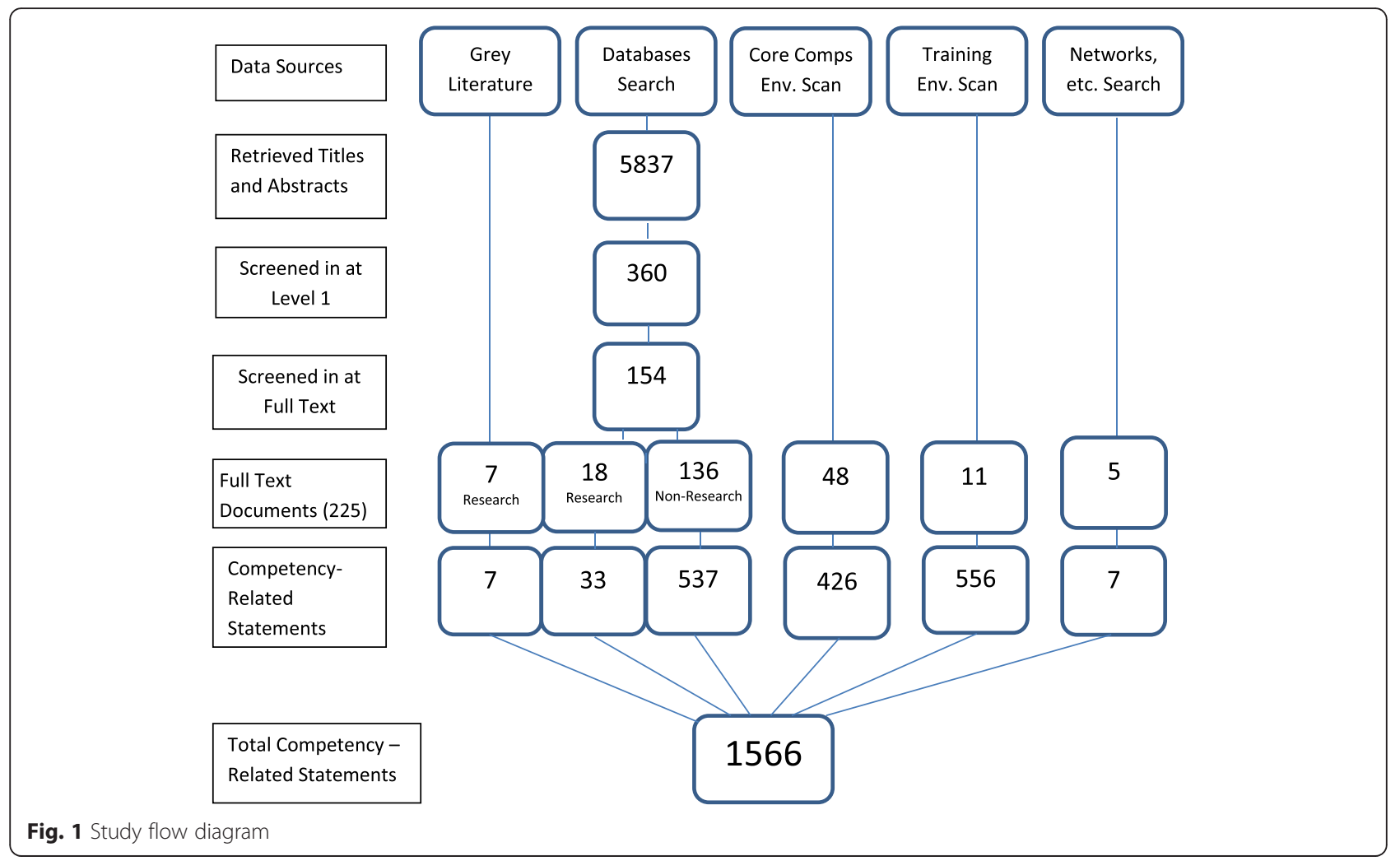

research. Fifteen studies were survey-based research, three were descriptive studies, three were case studies, and two were final project reports (one from a task force and the other from a study funded by the US National Institute of Education). The remaining two studies were a systematic review and a mixed-methods study. Five studies reported receiving funding. Nineteen studies were published in different journals and the remaining six were part of the Peer Review Congress Proceedings. Publication dates ranged from 1975 to 2014; 2009 was the year with the most publications $(n=3)$, followed by $2011(n=2)$ and $2013(n=2)$. Twelve of the studies' first authors were from the USA, 10 from the United Kingdom, and one each from Iran, India, and Canada. The publications produced a total of 40 competency-related statements (i.e. possible competencies), with individual publications yielding between zero and 14 statements and a median of one statement per publication.

\section{Expanded scoping exercise}

Non research-based publications A total of 136 nonresearch-based publications were considered relevant to core competencies for scientific editors of biomedical journals, yielding a total of 537 competency-related statements (Additional file 2). Similar to the researchbased literature, none of these publications had the explicit goal of outlining a set of core competencies for scientific editors. Overall, 133 publications were editorial in nature, while the remaining three included a lecture, a job description, and an interview. Seventeen journals had multiple included publications, with three of them (Australian and New Zealand Journal of Obstetrics and Gynaecology, Croatian Medical Journal, and Indian Journal of Medical Sciences) producing three publications each while the other 14 journals had two publications each. JAMA also had four publications across three journals in its collection (JAMA, JAMA Internal Medicine, JAMA Ophthalmology). The rest of the sample consisted of a single publication per journal. The date of publication ranged from 1954 to 2015; $2011(\mathrm{n}=20)$ and $2012(\mathrm{n}=17)$ were the 2 years with the most studies. The sample included 66 studies with first authors originating from the USA and 19 from the United Kingdom, with representation from another 18 countries as well among first authors. The individual publications yielded between zero and 15 competencyrelated statements, with a median of two statements per publication.

Environmental scan of training in Journalology We reviewed all 258 documents listed in the Repository of Ongoing Training Opportunities in Journalology [20], which houses all of the data from an environmental scan of training in Journalology carried out by members of 
Table 1 Included research-based publications

\begin{tabular}{|c|c|c|c|c|c|c|c|}
\hline First author & Affiliation & Country & Journal & Year & Design & $\#^{a}$ & Item(s) ${ }^{b}$ \\
\hline Albert, $T$ & Tim Albert Training & UK & Learned Publishing & 2002 & Survey & 0 & N/A \\
\hline Barnes, M & University of Nebraska-Lincoln & USA & The Review of Higher Education & 1986 & Survey & 5 & $5,72,170,171,185$ \\
\hline Carroll-Johnson, R & Oncology Nursing Society & USA & Nurse Author \& Editor & 1996 & Survey & 1 & 137 \\
\hline Davis, RM & Henry Ford Health System & USA & Science \& Engineering Ethics & 2002 & Survey & 1 & 137 \\
\hline de Jesus Mari, J & $\begin{array}{l}\text { King's College, University } \\
\text { of London }\end{array}$ & UK & African Journal of Psychiatry & 2009 & Task Force Report & 0 & N/A \\
\hline Etemadi, A & $\begin{array}{l}\text { Shaheed Beheshti University } \\
\text { of Medical Sciences }\end{array}$ & Iran & Saudi Medical Journal & 2004 & Survey & 1 & 141 \\
\hline Freda, M & Journal of Nursing Scholarship & USA & Journal of Nursing Scholarship & 2005 & Survey & 0 & N/A \\
\hline Froehle, $T$ & Indiana University, Bloomington & USA & Counselor Education \& Supervision & 1990 & Descriptive Study & 0 & $\mathrm{~N} / \mathrm{A}$ \\
\hline Galipeau, J & $\begin{array}{l}\text { Ottawa Hospital Research } \\
\text { Institute }\end{array}$ & Canada & Systematic Reviews & 2013 & Systematic Review & 0 & N/A \\
\hline Garrow, J & $\begin{array}{l}\text { LOCKNET Peer Review Research } \\
\text { Group: European Journal of } \\
\text { Clinical Nutrition }\end{array}$ & UK & $\begin{array}{l}\text { Journal of the American Medical } \\
\text { Association }\end{array}$ & 1998 & Survey & 0 & N/A \\
\hline Grindlay, D & $\begin{array}{l}\text { Centre for Evidence-based } \\
\text { Veterinary Medicine, School } \\
\text { of Veterinary Medicine and } \\
\text { Science, The University of } \\
\text { Nottingham }\end{array}$ & UK & BMC Veterinary Research & 2014 & Survey & 1 & 148 \\
\hline Hing, $C$ & $\begin{array}{l}\text { Department of Trauma \& } \\
\text { Orthopaedics, St George's } \\
\text { Hospital, Tooting, UK }\end{array}$ & UK & $\begin{array}{l}\text { Journal of Orthopaedic Surgery \& } \\
\text { Research }\end{array}$ & 2011 & Survey & 0 & N/A \\
\hline Kearney, M & $\begin{array}{l}\text { University of Rochester School } \\
\text { of Nursing }\end{array}$ & USA & Nursing Outlook & 2006 & Descriptive Study & 13 & $\begin{array}{l}5,26,30,35,69,72,83, \\
84.85,91,102,178,203\end{array}$ \\
\hline Kleinert, S & The Lancet & UK & Peer Review Congress (Abstract) & 2005 & Observational Study & 0 & N/A \\
\hline Lebeau, DL & Tulane University Medical Center & USA & Peer Review Congress (Abstract) & 1997 & Survey & 1 & 72 \\
\hline Logothetti, H & Obstetrics \& Gynecology & USA & Peer Review Congress (Abstract) & 2009 & Case-Control & 1 & 101 \\
\hline Patrone, D & $\begin{array}{l}\text { Philosophy Department, State } \\
\text { University of New York at } \\
\text { Oneonta/Broome Community } \\
\text { College, Binghamton, New York }\end{array}$ & USA & $\begin{array}{l}\text { Biosecurity and Bioterrorism: } \\
\text { Biodefense Strategy, Practice, } \\
\text { and Science }\end{array}$ & 2012 & Survey & 2 & 147,203 \\
\hline Radford, D & $\begin{array}{l}\text { Division of Prosthetic Dentistry, } \\
\text { King's and St Thomas' Dental } \\
\text { Institute, London }\end{array}$ & UK & British Dental Journal & 1999 & Survey & 0 & $\mathrm{~N} / \mathrm{A}$ \\
\hline Reynolds, T & Highland Hospital & USA & Peer Review Congress (Abstract) & 2009 & Survey & 0 & N/A \\
\hline Silverman, $\mathrm{R}$ & Ohio State University & USA & None (Final Report) & 1975 & Final Report & 6 & $79,91,101,166,194,203$ \\
\hline Srinivasan, S & Indian J Medical Ethics & India & Peer Review Congress (Abstract) & 2013 & Survey & 0 & N/A \\
\hline Wager, E & Sideview, Princes Risborough & UK & Peer Review Congress (Abstract) & 2009 & Case Analysis & 0 & N/A \\
\hline Wager, E & Sideview, Princes Risborough & UK & The British Medical Journal & 2013 & $\begin{array}{l}\text { Quantitative + } \\
\text { Interviews }\end{array}$ & 1 & 136 \\
\hline Williams, P & University College London & UK & Science and Engineering Ethics & 2011 & Case Studies & 2 & 58,203 \\
\hline Wong, V & $\begin{array}{l}\text { Department of Neurology, } \\
\text { University of Michigan, } \\
\text { Ann Arbor }\end{array}$ & USA & Journal of Clinical Epidemiology & 2011 & Survey & 5 & $2,118,123,203(2)$ \\
\hline \multicolumn{6}{|l|}{ TOTAL } & 40 & \\
\hline
\end{tabular}

${ }^{a}$ Number of competency statements extracted from the document

${ }^{\mathrm{b}}$ Corresponds to the item number from the list of competency-related statements (Table 3)

our team in 2013. From this repository, we extracted 11 relevant non-research-based articles from which we were able to retrieve 556 competency-related statements relating to scientific editors of biomedical journals (Table 2). Seven of these documents were from organizations that provide guidance to editors (e.g. WAME, 
Table 2 Included documents from expanded scoping exercise

GUIDANCE FROM EDITORIAL GROUPS

\begin{tabular}{llll}
\hline Title & Editorial group/organization & Scanning source & \# $^{\text {a }^{\prime}}$ Item(s) $^{\text {b }}$ \\
\hline International Standards for Authors & Committee on Publication & Training & $58(2), 9,10,11,12(2), 20(6), 22(3), 25,26$, \\
& Ethics (COPE) & $34,35(3), 39,46,57(2), 64,72(5), 79(2)$, \\
& & $108(2), 137(2), 138(4), 140,141(4), 143$, \\
& & $144,145,146(3), 150,159,198,199,203$
\end{tabular}

Guidelines for Editors

COPE

Training

COPE

A Short Guide to Ethical Editing for New Editors

Council of Science Editors (CSE)

A Science Editing Course for Graduate Students

Can Non-Native-English-Speaking

Editors be Effective Editors of

English-Language Writing?

Guidelines for Reporting Health

Research: How to Promote their

Use in Your Journal

Research Ethics, Publication Ethics

and Good Practice Guidelines

European Association of Science Editors (EASE) Toolkit for Journal Editors

Editor's Handbook (2nd Edition)

Golden Rules for Scholarly Journal Editors

Recommendations for the Conduct, Reporting, Editing, and Publication of Scholarly Work in Medical Journals

Responsibilities in the Submission and Peer Review Process (Journals)

Syllabus for Prospective and Newly Appointed Editors

Outline of Planned WAME Journal Editor Training
$2,6,16,19,20,21,22(2), 24,25,26(2)$ (2), 32, 34, 35(4), 39, 41, 42, $88,104,111,137(2), 138,139,141(2)$ $143,146,150,153(2), 159,189,194$, 197, 198, 199(2), 203(7) $36,48(2), 62,68,72,104,116,136$ $137(2), 138,144(2), 189,197,203(5)$ $25,78,95,100(2), 126(2), 127,132$ $138,141,178,199$ $22(4), 24(2), 25,26(2), 27(2), 28,30,31$ $32,33,35(3), 36,39(2), 48,50(3), 52(2)$ 69(2), 70, 71,72(2), 73(2), 77, 78, 79(2), $83(2), 84,85(3), 87,89(2), 91(2), 92,93$, $96(2), 98,105,108(2), 109(3), 111,113$, 135(2), 137(2), 138(2), 139(4) 159, 167, 171, 194, 197, 199(2), 200(2), 201(3), 202(2), 203(8) 35,140
$6,15,35,72(2), 85,89,111,138,149$
EASE

International Committee of Medical Journal Editors (ICMJE)

ICMJE

World Association of Medical Editors (WAME)

WAME

Training

Core competencies

Core competencies

Training

9

Training

56

$47,48(2), 52,57(6), 61(2), 62,72(2), 79$ $83,84,91,92,106,113,119,137,139$, 141(2), 146(2), 159, 189, 197(2), 203(9)

84 $52,56(2), 59,61,64(3), 65(3), 66,68(5)$, $70,72,74,75,76,80,81,84,90,91(2)$, $106,109,113(4), 124(3), 127,128,132$, $133(2), 135(2), 136,137,140,141(5)$, $142,144,145,146,152,154,155(3)$, $159,162(2), 166,198,203(4)$
ASSOCIATIONS, JOURNALS, PUBLISHERS

Editor Handbook
Alliance of Crop, Soil, and Environmental Sciences Society
Core competencies 
Table 2 Included documents from expanded scoping exercise (Continued)

\begin{tabular}{|c|c|c|c|c|}
\hline Editors and Reviewers & $\begin{array}{l}\text { Alliance of Crop, Soil, and } \\
\text { Environmental Sciences Society }\end{array}$ & Core competencies & 11 & $6(3), 35(2), 47,61,112(2), 140,141$ \\
\hline Editor Handbook & $\begin{array}{l}\text { American Association of } \\
\text { Pharmaceutical Scientists Journal }\end{array}$ & Core competencies & 9 & $35,91,116(2), 203(5)$ \\
\hline Editor-In-Chief: Position Description & American Geophysical Union & Core competencies & 25 & $\begin{array}{l}69,72,84,95,140,159,160,161 \\
162(2), 166,167,170(2), 171(2), 178 \\
181(2), 182,189,191(2), 199,203\end{array}$ \\
\hline $\begin{array}{l}\text { Position Description for the AJNR Editor } \\
\text { and Basic Qualifications }\end{array}$ & American Journal of Neuroradiology & Core competencies & 5 & $5,70,91,117,168$ \\
\hline Responsibilities of an Editor & $\begin{array}{l}\text { Annals, Academy of Medicine, } \\
\text { Singapore }\end{array}$ & Training & 30 & $\begin{array}{l}6(2), 17,19,35(2), 61,73,77,79,80 \\
81,83,90(4), 91,92,137(4), 138,151 \\
172,192,203(3)\end{array}$ \\
\hline $\begin{array}{l}\text { What does an Associate Editor } \\
\text { Actually do? }\end{array}$ & Association for Computing Machinery & Core competencies & 3 & $34,40,72$ \\
\hline The Role of the Scientific Editor & British Dental Journal & Core competencies & 3 & $8,14,20$ \\
\hline $\begin{array}{l}\text { Recruiting a Journal Editor: An HSS } \\
\text { Challenge }\end{array}$ & Cambridge Journals Blog & Core competencies & 0 & N/A \\
\hline Editorial: on Editing and Being an Editor & Cultural Studies of Science Education & Core competencies & 3 & $6,33,34$ \\
\hline Editor's Pack & Elsevier & Publishers search & 0 & N/A \\
\hline $\begin{array}{l}\text { How do Publishers Choose Editors, and } \\
\text { How do they Work Together? }\end{array}$ & Elsevier & Core competencies & 7 & $110,160,162,184,185,194,203$ \\
\hline Publishing Ethics Resource Kit (PERK) & Elsevier & Publisher search & 0 & N/A \\
\hline $\begin{array}{l}\text { European Respiratory Journal } \\
\text { Editor(s)-in-Chief }\end{array}$ & European Respiratory Society & Core competencies & 6 & $162(2), 165,167,195,178$ \\
\hline Editor-in-Chief (position description) & $\begin{array}{l}\text { International Society of Exposure } \\
\text { Science; Journal of Exposure Science } \\
\text { and Environmental Epidemiology }\end{array}$ & Core competencies & 9 & $19,35,101,138,159,165,166,170,203$ \\
\hline Editor-in-Chief (position description) & $\begin{array}{l}\text { Journal of Family Planning and } \\
\text { Reproductive Health Care }\end{array}$ & Core competencies & 19 & $\begin{array}{l}8,19(2), 36,95,116,117,121,123(2) \\
127,138,159,164,167,170,178,180 \\
181\end{array}$ \\
\hline Responsibilities of the Editor & Journal of Medical Internet Research & Core competencies & 1 & 123 \\
\hline Responsibilities of the $\mathrm{JNCl}$ Editor in Chief & $\begin{array}{l}\text { Journal of the National Cancer } \\
\text { Institute }\end{array}$ & Core competencies & 8 & $95,99,127,132,138,159,174,203$ \\
\hline Responsibilities of Editors and Reviewers & $\begin{array}{l}\text { Online Ethics Center for Engineering } \\
\text { and Science }\end{array}$ & Core competencies & 0 & N/A \\
\hline Scientific Editing-A Wise Career Choice & Science Careers (from the journal Science) & Core competencies & 0 & N/A \\
\hline $\begin{array}{l}\text { Horses for Courses-Research Papers } \\
\text { versus Reviews }\end{array}$ & Science Careers (from the journal Science) & Core competencies & 0 & N/A \\
\hline The Editors' World: Back to the Books & Science Careers (from the journal Science) & Core competencies & 6 & $159(2), 165,175,178,181$ \\
\hline $\begin{array}{l}\text { Bench to Page: An Editor's View of } \\
\text { Science Publishing }\end{array}$ & Science Careers (from the journal Science) & Core competencies & 3 & $73,164,170$ \\
\hline At the Gateway of Cutting-Edge Research & Science Careers (from the journal Science) & Core competencies & 7 & $68,108,109,122,162,163,191$ \\
\hline $\begin{array}{l}\text { Translating Scientific Expertise into } \\
\text { Publishing Success }\end{array}$ & Science Careers (from the journal Science) & Core competencies & 0 & N/A \\
\hline Journal Editors Get Twitter-Savvy & Science Careers (from the journal Science) & Core competencies & 14 & $\begin{array}{l}40,71,73,90,93,95,108,164,165 \\
174,177,185,193,196\end{array}$ \\
\hline $\begin{array}{l}\text { Careers in Neuroscience/Career Paths: } \\
\text { Science Publishing }\end{array}$ & Society for Neuroscience & Core competencies & 8 & $122,164,165,166,167(2), 178,184$ \\
\hline $\begin{array}{l}\text { Academic Journal Editors' Professionalism: } \\
\text { Perceptions of Power, Proficiency and } \\
\text { Personal Agendas }\end{array}$ & Society for Research Into Higher Education & Core competencies & 9 & $33(2), 72,73,110,121,160,167,174$ \\
\hline Editorial Guide & Springer & Publishers search & 7 & $26,65,78,82,85,138,197$ \\
\hline
\end{tabular}


Table 2 Included documents from expanded scoping exercise (Continued)

\begin{tabular}{|c|c|c|c|c|}
\hline Trainee Programs/Editorial Trainees & Springer & Core competencies & 0 & $\mathrm{~N} / \mathrm{A}$ \\
\hline Confessions of a Journal Editor & The Chronicles of Higher Education & Core competencies & 0 & $\mathrm{~N} / \mathrm{A}$ \\
\hline $\begin{array}{l}\text { Ethics and the Psychiatry Journal Editor: } \\
\text { Responsibilities and Dilemmas }\end{array}$ & $\begin{array}{l}\text { The Israel Journal of Psychiatry and } \\
\text { Related Sciences }\end{array}$ & Core competencies & 9 & $20(2), 22,36,48,64,120,140,141$ \\
\hline Editor Ethics 2.0 Code/Affirming Editors & University of North Carolina - Charlotte & Core competencies & 2 & 20,138 \\
\hline $\begin{array}{l}\text { UOJM Editor Training: Results from the } \\
2013 \text { Editor Satisfaction Survey and } \\
\text { Highlights from 2013-2014 Training } \\
\text { Workshops }\end{array}$ & University of Ottawa Journal of Medicine & Core competencies & 8 & $36,61,74,79,95,123,160,175$ \\
\hline FAME Guidelines & World Health Organization & Training & 35 & $\begin{array}{l}6(3), 10,14,15,30,34,35,39,40(2) \\
47,61,72(3), 75,79(2), 91,92,133 \\
138(2), 141,143,149,159(2), 179,189 \\
198,203(2)\end{array}$ \\
\hline Research Journal Editor Position Description & Young Adult Library Service Association & Core competencies & 11 & $\begin{array}{l}35,95(2), 117,159,160,161,162,167 \\
174,180\end{array}$ \\
\hline \multicolumn{5}{|l|}{ OTHER SOURCES } \\
\hline Medical/Scientific Editor (job posting) & Alexion Pharmaceuticals, Inc. & Core competencies & 0 & N/A \\
\hline Duties of Editors & Bioinfo Publications & Core competencies & 3 & $104,141,199$ \\
\hline What is Special about Science Editing? & Biotext & Core competencies & 11 & $\begin{array}{l}120,124,125,129(2), 130,131,141 \\
165,175,193\end{array}$ \\
\hline What is Different about Science Editing? & Emend Editing & Core competencies & 13 & $\begin{array}{l}57,60,117,125,126,127,129,130 \\
131,162,165,175,193\end{array}$ \\
\hline What Exactly Does an Editor Do? & Joseph Alpert & Training & 11 & $\begin{array}{l}39,54,68,73,86,108,138,162 \\
198,203(2)\end{array}$ \\
\hline Becoming a Journal Editor & PhD2Published & Core competencies & 5 & $109,167,182,190,199$ \\
\hline Public Knowledge Project School & Public Knowledge Project & Training & 67 & $\begin{array}{l}6(3), 14,15(8), 20,26(3), 30,34,35(3), \\
39,46,47,50,53(3), 57(2), 59,61(2), \\
62,68,84,85,87,91,95,104(2), 137(2), \\
138,140,141,149,160,167(2), 197(2), \\
203(14)\end{array}$ \\
\hline $\begin{array}{l}\text { What does an Editor (a Member of } \\
\text { Editorial Board) do Exactly in Journals? }\end{array}$ & ResearchGate & Core competencies & 0 & N/A \\
\hline $\begin{array}{l}\text { What are the Role and Duties of a } \\
\text { Scientific Editor of an Academic } \\
\text { Peer-Review Journal? }\end{array}$ & ResearchGate & Core competencies & 5 & $44,72,79,159,203$ \\
\hline Job Description of an Editor-in-Chief & Study.com & Core competencies & 0 & N/A \\
\hline $\begin{array}{l}\text { So, you want to be a Science Writer } \\
\text { when you grow up }\end{array}$ & The Black Hole & Core competencies & 0 & $\mathrm{~N} / \mathrm{A}$ \\
\hline Ideas for a Topical Outline & Unknown & Training & 103 & $\begin{array}{l}2,8(2), 10,14,15,17,20,22,26(3), 31, \\
33,37,48,49,50,51,52,53,56(2), 57 \\
59(2), 61(2), 62,64(3), 66,68(4), 70,71, \\
72,74,75,76,77(2), 81,82,91(3), 92, \\
95,101,106(2), 113(3), 117,124(3), 127, \\
133(4), 135(2), 136,137,140,141(3), \\
142,144,145,146,147,152,154, \\
155(3), 161,162(2), 165(2), 169(2), 173, \\
198,203(9)\end{array}$ \\
\hline $\begin{array}{l}\text { Recommended Recruitment Steps for } \\
\text { Journal Editor, CJNSE/RCJCÉ }\end{array}$ & Wired Learning Consultants & Core competencies & 6 & $95,117,162,167,178(2)$ \\
\hline How do I Become a Science Editor? & WiseGEEK & Core competencies & 0 & N/A \\
\hline TOTAL & & & 989 & \\
\hline
\end{tabular}

\footnotetext{
${ }^{\mathrm{a}}$ Number of competency statements extracted from the document

${ }^{b}$ Corresponds to the item number from the list of competency-related statements (Table 3)
} 
COPE, International Committee of Medical Journal Editors) and the remaining documents were from a variety of other sources.

Environmental scan of core competencies for scientific editors of biomedical journals The environmental scan carried out for this project consisted of a total of 40 keyword searches (Additional file 1) that yielded 48 relevant documents, of which 35 were deemed to meet the eligibility criteria after screening in duplicate. These 35 documents produced 426 competency-related statements (Table 2). Among the sample, 18 documents were produced or published by journals, nine were from associations and societies, six were from organizations providing guidance to editors, and two were from publishers.

Search of networks, publishers, and meetings A search of networks, publishers, and meetings produced an additional five documents, three of which were documents from publishers' websites and two from the EQUATOR Network (Table 2). We extracted seven competency-related statements from these additional documents.

Of the 64 documents in the expanded scoping exercise, the European Association of Science Editors Editor's Handbook (2nd Edition) [22] had the highest number of competency-related statements $(n=166)$. The median number of competency-related statements across the scoping exercise documents was six.

\section{Collating and summarizing the data}

The combined 1,566 competency-related statements originating from the 225 total documents were collated and then de-duplicated, producing a list of 203 unique statements (i.e. possible competencies of scientific editors) (Table 3). The statements were organized into seven categories that emerged from the data: (1) dealing with authors; (2) dealing with peer reviewers; (3) journal publishing; (4) journal promotion; (5) editing; (6) ethics and integrity; and (7) qualities and characteristics of editors.

\section{Discussion}

This scoping review identified 225 relevant publications, spanning more than 60 years, and involving authors from more than 20 countries. It produced a comprehensive list of possible competency-related statements for the scientific editor position within biomedical journals. This categorized list of statements will be used in a subsequent Delphi exercise aiming to ask a broad spectrum of scientific editors of biomedical journals to rate the importance of each statement in relation to performing their duties as a scientific editor. This data will then help inform a consensus meeting in which a select group of editors will collaborate to outline a set of core competencies.

Despite our finding that the competencies of editors have been discussed in the published literature since the mid-1950s, a recent systematic review [17] found no comparative studies of the effectiveness of training for editors. This is concerning, given the gate-keeping role that scientific editors play as guardians of the scientific record [23]. Trends in the number of publications annually would seem to indicate that, while the overall number of publications in this area has grown since the topic first emerged in the literature, interest peaked around 2011 and is now waning. The trend, however, is more reflective of editorial-type articles in journals, which have declined since 2011, while the number of researchbased publications has remained relatively stable (yet sparse) during the same timeframe.

One possibility for the decline in total publications is that organizations may believe these issues have already been identified and they are working on training materials for them rather than publishing more research or commentaries about them in medical journals. A possibility for the continued lack of research in this area may be that the focus of many major funding agencies is to fund by disease (e.g. heart, kidney, cancer, diabetes). As journal editing, and the field of journalology more broadly, is a domain that spans across the spectrum of research on diseases, it is often difficult to find appropriate funding opportunities and even more difficult to convince specific disease-based funding agencies that the research merits their funding investment.

A major challenge that we anticipated as part of this scoping review was that a large proportion of the evidence may not be in the traditional research-based literature. For this reason, we placed a heavy emphasis on extensively searching the grey and non-research-based literature by including two related environmental scans as part of the larger program on core competencies for scientific editors of biomedical journals. However, it is still possible that we may not have captured every aspect of a biomedical editor's work in our searches. In particular, some of the more tacit (e.g. difficult to describe) aspects of the work of editors may simply not be documented, or may reside in documents that may not necessarily be found in a database or Google search (e.g. resources residing behind membership or passwordprotected webpages, paywalls). We expect that any critical missing items will be brought forth in the training needs assessment, the Delphi, or the consensus meeting. Additionally, because of the subjective nature of this type of data extraction, it is possible that some competency-related statements were missed within the included publications. However, we feel that the likelihood of this was reduced as several members of the 
Table 3 Competency-related statements ${ }^{\text {a }}$

\begin{tabular}{|c|c|c|}
\hline Item \# ${ }^{\text {b }}$ & Competency-related statement & $\#^{c}$ \\
\hline \multicolumn{3}{|c|}{ I. Dealing with authors } \\
\hline \multicolumn{3}{|c|}{ Scientific editors should: } \\
\hline 1 & Review study protocols and methods and encourage authors to make them publicly available & 1 \\
\hline 2 & Ensure authors are aware of ethical authorship practices & 5 \\
\hline 3 & Seek to help authors understand magnitude of effect & 1 \\
\hline 4 & Assist potential authors in developing a spirit of inquiry & 1 \\
\hline 5 & Develop wide acquaintance with potential authors & 4 \\
\hline 6 & Demonstrate accountability to authors and ensure they are treated with fairness, courtesy, and objectivity & 36 \\
\hline 7 & Provide constructive criticism to authors & 3 \\
\hline 8 & Engage in mentorship and education of authors to help them produce work to best effect & 30 \\
\hline 9 & Mediate sound communication between the comments of reviewers and responses of authors & 4 \\
\hline 10 & Ensure publication decisions are clearly communicated to all authors & 7 \\
\hline 11 & Interact with authors to confirm undisputed changes in authorship and act on any institutional findings concerning authorship disputes & 1 \\
\hline 12 & Clarify the peer-review processes to authors & 2 \\
\hline 13 & Negotiate manuscript publication delays with authors & 1 \\
\hline 14 & Deal with authors who appeal against rejection & 7 \\
\hline 15 & Ensure authors are informed about journal and article information and/or funding & 13 \\
\hline 16 & Ensure that requests from authors that an individual not review their submission are respected, if these are well-reasoned & 2 \\
\hline 17 & Engage in critical evaluation of authors' manuscripts and the peer-review process itself & 3 \\
\hline 18 & Provide active encouragement for revisions of manuscripts & 2 \\
\hline 19 & Demonstrate experience as a competent author, academic, researcher, or reviewer & 6 \\
\hline 20 & Demonstrate proficiency in dealing with author misconduct and other issues related to publication ethics & 35 \\
\hline 21 & Work with publishers to defend author rights and pursue offenders & 1 \\
\hline 22 & Act on concerns about plagiarism, data fabrication, or an authorship issue and follow-up with authors and then institutions & 13 \\
\hline 23 & Request full disclosure of potential conflicts of interest by the authors & 2 \\
\hline 24 & Support authors in dealing with breaches of copyright and plagiarism issues & 4 \\
\hline 25 & Request appropriate documentation from authors when they submit manuscripts & 6 \\
\hline
\end{tabular}

II. Dealing with peer reviewers

26 Develop, facilitate, and monitor the peer review process 32

$27 \quad$ Knowledge of different types of peer review 4

28 Encourage and demonstrate awareness of new findings on peer review and publishing and how these influence their journal's 3 processes

29 Review revised manuscripts 1

$30 \quad$ Provide guidance to peer reviewers 11

$31 \quad$ Ensure thorough statistical review 3

$32 \quad$ Ensure that peer review panels for individual papers are not biased 4

33 Evaluate and provide feedback to the reviewers on review quality 9

$34 \quad$ Ensure manuscript content is matched with the expertise of particular reviewers 13

35 Monitor and ensure the fairness, timeliness, thoroughness, and civility in the processing of manuscripts and in responding to 37 queries from authors and reviewers

36 Demonstrate knowledge of the workings of the peer review process 7

37 Train peer reviewers 2

$38 \quad$ Ensure reviewer comments are shared with all peer reviewers 1

39 Synthesize reviews and make ultimate editorial decisions in light of peer reviewers' comments 10

$40 \quad$ Evaluate manuscripts in light of reviewers' critiques and various selection criteria 5 
Table 3 Competency-related statements ${ }^{a}$ (Continued)

$41 \quad$ Demonstrate the ability to distinguish between objective peer reviewed research and reviews from opinion and the journal content 2 from advertising and other promotional content

$42 \quad$ Ensure reviewers who consistently produce discourteous, poor quality, or late reviews are removed from the journal's pool of peer 1 reviewers

$43 \quad$ Ensure a decision is made on a manuscript when reviewers fail to submit a timely review 1

$44 \quad$ Ensure a very high standard of the referees, don't accept sloppy reports from anyone

45 Demonstrate publication and reviewing skills and experience

46 Ensure that reviewers keep manuscripts, associated material, and the information they contain strictly confidential

47 Demonstrate sound judgment in the acceptance of research articles, editorials, and reviews that touch on current issues

III. Journal publishing

48 Demonstrate knowledge of marketing and advertising policies, including ethical issues 9

49 Demonstrate knowledge of the article embargo process 1

$50 \quad$ Demonstrate knowledge of indexing services 7

$51 \quad$ Demonstrate knowledge of reprint processes 2

52 Demonstrate knowledge of the specifications of the journal 5

53 Demonstrate knowledge of the goals of the journal 4

54 Demonstrate knowledge of formatting of layout for journal issues 6

55 Ensure the content of manuscripts submitted for publication is checked for accuracy

Demonstrate knowledge of the different parts, purposes, and characteristics of different types of journals 4

Demonstrate understanding of the editorial office and operations 22

Ensure that selected/published research is correct 2

Demonstrate knowledge about legal issues relating to the position of scientific editor 5

Be aware of how design can be used to improve the readability of a document 1

Demonstrate understanding of one's responsibilities and rights as a journal editor 14

Demonstrate knowledge of the roles and responsibilities of the editorial staff 4

Identify and address issues related to data protection and confidentiality 2

Demonstrate knowledge of journal metrics and research impact 9

Demonstrate knowledge of online publishing and products 13

Demonstrate knowledge of the parts, purposes, and characteristics of audio and video clips 2

Demonstrate awareness of intellectual property issues and work with publisher to handle potential breaches

Demonstrate knowledge of technical-economical aspects of medical journal production 16

Explore and embrace innovative technologies 5

Maintain close contact with the latest trends in electronic media (e.g. tablets) 4

Engage in multimedia publishing practices 3

$72 \quad$ Act as a gatekeeper and guarantor of publications, checking both the quality and scope of research published in the journal 81

IV. Journal promotion

$73 \quad$ Maintain knowledge of important developments and trends in one's own field 10

74 Demonstrate knowledge of history of journals and scientific publications

75 Demonstrate knowledge of national and regional variations between journals

76 Demonstrate knowledge of political and geopolitical issues 2

77 Demonstrate familiarity with associations and their educational resources 5

78 Stay on top of updates in one's field 3

79 Demonstrate knowledge of, and work to maintain and improve the journal's policies, vision, scope, content, processes, and goals 20

80 Ensure decisions are based on the validity of the work and its importance to the journal's readers 4

81 Ensure controversial topics (political, ethical) are dealt with 3

$82 \quad$ Stimulate others to write articles and editorials 3 
Table 3 Competency-related statements ${ }^{a}$ (Continued)

\begin{tabular}{lll}
\hline 83 & Engage in the promotion of scholarly research and best practices in conducting and reporting it \\
84 & Entice leading researchers to submit to the journal \\
85 & Serve as ambassador for the journal in establishing its visibility and image \\
86 & Motivate physicians to read, ponder, and implement the information provided \\
87 & Seek feedback/opinions on the journal \\
88 & Enhance public understanding of science \\
89 & Demonstrate understanding of who one's constituency is \\
90 & Demonstrate a responsibility to the scientific community \\
91 & Hold paramount the interests of the particular journal's readers \\
92 & Engage in communication with the public & 4 \\
93 & Engage with existing and new scientific communities & 4
\end{tabular}

V. Editing

94 Demonstrate knowledge of policies for submission of manuscripts

Demonstrate broad and detailed knowledge of the skills needed to refine a piece of scientific work and shepherd it through to publication

96 Demonstrate knowledge of typography

Demonstrate knowledge of and experience with online editing

Demonstrate knowledge of the fundamentals of editing various types of science copy 3

Enforce ICMJE authorship guidelines

Ensure logic and consistency of manuscripts

Ensure papers selected are clinically relevant

Demonstrate the ability to select material for its merit, interest to readers, and originality alone

Ensure papers selected are suitable to the journal

Ensure manuscripts are triaged judiciously (for journals that use such a process)

Handle manuscripts in the areas of one's expertise and assist in finding persons qualified to handle papers in those areas outside one's expertise

Demonstrate aptitude in using technology (computers, Internet, e-mail, Manuscript Submission Systems) to perform his or her editorial duties)

Possess a degree in medical editing or be trained as a journal editor 
Table 3 Competency-related statements ${ }^{a}$ (Continued)

\begin{tabular}{lll}
\hline 125 & Demonstrate familiarity with scientific units, numerals, symbols, and nomenclature & 17 \\
126 & Demonstrate familiarity with the presentation of data and data presentation problems & 3 \\
127 & Demonstrate familiarity with the basic concepts of statistics & 12 \\
128 & Demonstrate knowledge of literature reviews \\
129 & Demonstrate familiarity with the principles of scientific investigation \\
130 & Demonstrate familiarity with types of evidence \\
131 & Demonstrate familiarity with scientific referencing \\
132 & Demonstrate familiarity with clinical research design \\
133 & Demonstrate knowledge of types of manuscripts \\
134 & Be working towards a deeper understanding of multiple research epistemologies \\
135 & Assist non-native speakers in dealing with language issues & 3
\end{tabular}

\section{Ethics and integrity}

136 Demonstrate knowledge of issues around registration (i.e. trials, systematic reviews, protocols) 4

137 Demonstrate knowledge of and adherence to the principles of editorial independence 25

138 Demonstrate expertise in ensuring the ethical integrity of publications 33

$139 \quad$ Identify and address allegations of fraud or plagiarism 9

140 Demonstrate understanding of privacy, confidentiality, and anonymity issues 13

$141 \quad$ Identify and address issues related to conflicts of interest 34

$142 \quad$ Identify and address issues related to industry-sponsored research 6

143 Separate decision-making from commercial considerations 3

144 Demonstrate knowledge of the ethical approval process for research involving humans and animals 7

$145 \quad$ Ensure the respect and privacy of patients described in clinical studies 7

146 Safeguard the rights of study participants and animals 9

147 Demonstrate understanding of issues related to dual-use research (research with multiple purposes or applications) 2

$148 \quad$ Identify and apply appropriate reporting guidelines 5

149 Guarantee access to, and long term preservation of, the published information 3

$150 \quad$ Encourage debate on important topics related to the journal 2

$151 \quad$ Promote higher standards of medical journalism 1

$152 \quad$ Identify and work to avoid publication bias 3

153 Demonstrate knowledge of COPE resources for editors, authors, and peer reviewers 5

154 Demonstrate knowledge of copyright issues 2

155 Demonstrate knowledge regarding problems with multiple publications (e.g. salami, duplicate, redundant) 9

$156 \quad$ Identify and address incongruities and bias in manuscripts 1

157 Recommend publication of papers that meet standards of scientific rigor 2

$158 \quad$ Identify and address issues related to image manipulation 2

VII. Qualities and characteristics of editors

159 Demonstrate experience and broad knowledge of the field(s) covered by the journal and of the people working in those fields

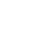
4 . 
Table 3 Competency-related statements ${ }^{a}$ (Continued)

\begin{tabular}{|c|c|}
\hline 167 & $\begin{array}{l}\text { Demonstrate excellent organizational, project, and time management skills, including the ability to work under considerable time } \\
\text { pressure }\end{array}$ \\
\hline 168 & Maintain part time professional practice \\
\hline 169 & Maintain membership in learned societies and editing-related associations \\
\hline 170 & Be recognized as a distinguished scholar in one's field \\
\hline 171 & Maintain an active research portfolio/is employed in a research-oriented university or institute \\
\hline 172 & Demonstrate past experience on an editorial board \\
\hline 173 & Demonstrates competence as a practitioner in their field \\
\hline 174 & Demonstrate strong interpersonal skills \\
\hline 175 & Demonstrate good analytical skills \\
\hline 176 & Demonstrate effective critical appraisal skills \\
\hline 177 & Demonstrate the ability to achieve consensus among opinionated scientists \\
\hline 178 & Demonstrate leadership skills \\
\hline 179 & Demonstrate political and public relations sense \\
\hline 180 & Demonstrate self-motivation \\
\hline 181 & Demonstrate enthusiasm \\
\hline 182 & Demonstrate tolerance and persistence \\
\hline 183 & Demonstrate boldness \\
\hline 184 & Demonstrate independent thinking \\
\hline 185 & Maintain visibility and respect among peers and in the larger scientific community \\
\hline 186 & Maintain rigid criteria \\
\hline 187 & Demonstrate the ability to perpetuate or challenge master narratives \\
\hline 188 & Exercise convictions with a positive attitude \\
\hline 189 & Demonstrate a willingness to reconsider decisions \\
\hline 190 & Demonstrate practicality \\
\hline 191 & Demonstrate decisiveness \\
\hline 192 & Demonstrate personal interest in medical journalology' or editology' \\
\hline 193 & Demonstrate an enjoyment of learning and a questioning mind \\
\hline 194 & Demonstrate the desire to advance their field of study \\
\hline 195 & Have access to a good academic network or have the potential to grow one \\
\hline 196 & Demonstrate patience when dealing with authors and reviewers \\
\hline 197 & Demonstrate knowledge of processes related to the editorial board \\
\hline 198 & Respond promptly to complaints \\
\hline 199 & Act with integrity and accountability \\
\hline 200 & Engage with social media to reach out beyond the usual specialist audiences \\
\hline 201 & Demonstrate knowledge of the parts, purposes, and characteristics of manuscripts \\
\hline 202 & Demonstrate knowledge of open access models \\
\hline
\end{tabular}

Other potential competencies

${ }^{a}$ The order in which the statements are presented is purely for purposes of organization and is not intended to convey any type of ranking

c Corresponds to the Item(s) columns in Tables 1 and 2

${ }^{b}$ Number of extracted competency-related statements across all data sources in the scoping review

${ }^{d}$ This item contains all statements pertaining only to potential competencies of Editors-in-Chief. Despite these potential competencies not being directly relevant to this scoping review, we nevertheless wanted to account for them in our results as they did fit our inclusion criteria

research team are editors. Finally, due to the broad inclusion criteria and the decision to preserve the wording used by authors to describe potential competencies as much as possible, it is likely that some items may not actually be competencies per se, but may instead describe tasks, behaviors, and knowledge related to competencies. 
However, these items are still useful in describing important aspects of editors' work and will therefore contribute valuable information for the development of core competencies.

With the large number of competency statements and our desire to create a manageable list for use downstream in our program of research, our efforts to remove redundant and overlapping items in order to streamline the list may also have led to the elimination of some nuances between items that were subtly different from one another. While we implemented measures to ensure consistency in our methods (i.e. piloted forms, duplication of the classification exercise), ultimately there is a degree of interpretation and selectivity embedded in this process. Thus, our list of possible competencies may not include all of the competencies of biomedical editors. As noted above, the next phases of this project are designed to elicit any missing items.

Another limitation is that for feasibility purposes we only considered English and French articles, which raises the possibility that relevant information published in another language was missed. Similarly, the databases searched may not have included some journals from outside fiscally resourced countries.

\section{Conclusion}

To our knowledge, this scoping review is the first attempt to systematically identify possible competencies of editors. On its own, the review will serve to inform readers on the extent and nature of existing literature in this area, as well as the breadth of skills, abilities, tasks, knowledge, and training that may be necessary to fulfill the position of scientific editor at a biomedical journal. More importantly, the review is part of a larger program to develop a minimum set of core competencies for scientific editors of biomedical journals.

The purpose of the 203 competency-related statements generated here is to be the central tool used for a Delphi exercise involving scientific editors of biomedical journals from around the world. Subsequently, these statements will serve to stimulate discussion at a consensus meeting in which the goal will be for relevant stakeholders to agree upon a minimum set of core competencies for scientific editors of biomedical journals. This evidence-based approach will ultimately lay the groundwork for the development of specific competency-based training and certification for scientific editors of biomedical journals [5]. The development of core competencies and subsequent training represent critical steps toward ensuring that the publication of biomedical research truly represents a hallmark of quality and trustworthiness, both within and beyond the research community.

\section{Additional files}

Additional file 1: Search strategies. (DOCX $23 \mathrm{~kb}$ )

Additional file 2: Non-research-based publications. (DOCX 49 kb)

\section{Abbreviations}

COPE: Committee on Publication Ethics; WAME: World Association of Medical Editors.

\section{Competing interests}

DM is supported by a University of Ottawa Research Chair. EW is a selfemployed consultant and provides training for editors, authors, and reviewers. She has received payment for such training from a variety of publishers, academic societies, universities, and commercial companies. She was also involved in developing the International Standards for Editors and many of the COPE guidelines. SB, MC, and HM are part of the Cochrane Central Editorial Unit. JD leads the Cochrane Collaboration's test evaluation activities. PG is a Coordinating Editor for the Cochrane Infectious Diseases Group. MW participated in the creation and dissemination of a survey to WAME members on medical journal editor professionalism in June 2015 and in the development of a series of sessions on medical journal editor professionalism for the WAME International Conference for Medical Journal Editors in New Delhi held in October 2015. JG, SS, LS, KDC, VB, PT, and $\mathrm{PB}$ all have no competing interests to declare.

\section{Authors' contributions}

DM conceived of the study, participated in its design and coordination, and helped to draft the manuscript. JG participated in the design of the study, coordinated the research, and was involved in title/abstract and full-text screening, data extraction and verification, and writing of the manuscript LS was involved in the design of the study, as well as participating in title/abstract and full-text screening, and data extraction and verification. SS was involved in the design of the study. KDC was involved in data extraction and verification. EW, SB, MC, HM, JD, MW, PG, VB, PT, and PB all provided content expertise. All authors were involved in the analysis and interpretation of data, revision of drafts of the manuscript, and reading and approving the final manuscript.

\section{Acknowledgments}

We thank Cochrane, the Committee on Publication Ethics (COPE), the World Association of Medical Editors (WAME), the European Association of Science Editors (EASE), and the Council of Science Editors (CSE) for their partnership in this scoping review. We thank Becky Skidmore for developing and running the search strategy and Raymond Daniel for acquiring, uploading, and managing records in DSR. We thank Jennifer Tetzlaff (JT) and Mona Ghannad (MG) for their involvement in screening titles and abstracts. This project is funded by Cochrane, Elsevier, and BioMed Central.

\section{Author details}

${ }^{1}$ Clinical Epidemiology Program, Ottawa Hospital Research Institute, Ottawa, Canada. ${ }^{2}$ School of Medicine, Griffith University, Queensland, Australia. ${ }^{3}$ American Academy of Neurology, St. Paul, Minnesota, USA. ${ }^{4}$ Department of Health Sciences, University of York, York, UK. ${ }^{5}$ School of Public Health and Preventive Medicine, Monash University, Melbourne, Australia. ${ }^{6}$ nstitute of Applied Health Research, College of Medical and Dental Sciences, University of Birmingham, Birmingham, UK. 'Liverpool School of Tropical Medicine, Liverpool, UK. ${ }^{8}$ Cochrane Editorial Unit, London, UK. ${ }^{9}$ Department of Medicine, University of Toronto, Toronto, Canada. ${ }^{10}$ School of Epidemiology, Public Health and Preventive Medicine, Faculty of Medicine, University of Ottawa, Ottawa, Canada. ${ }^{11}$ Sideview, Princes Risborough, UK. ${ }^{12}$ World Association of Medical Editors, Chicago, USA. ${ }^{13}$ Council of Science Editors, Colorado, USA. ${ }^{14}$ Cochrane Central Executive, London, UK. ${ }^{15}$ Department of Psychology, University of Stirling, Stirling, UK. ${ }^{16}$ Cochrane Learning and Support Department, London, UK. ${ }^{17}$ Department of Medicine Faculty of Medicine, University of Ottawa, Ottawa, Canada.

Received: 2 December 2015 Accepted: 20 January 2016 Published online: 02 February 2016 


\section{References}

1. Groves T. Enhancing the quality and transparency of health research. BMJ. 2008;337:a718

2. Smith R. Medical journals and the mass media: moving from love and hate to love. J R Soc Med. 2006;99(7):347-52.

3. Glasziou P, Altman DG, Bossuyt P, Boutron I, Clarke M, Julious S, et al. Reducing waste from incomplete or unusable reports of biomedical research. Lancet. 2014;383(9913):267-76.

4. Kleinert S, Horton R. How should medical science change? Lancet. 2014;383:197-8.

5. Moher D, Altman DG. Four proposals to help improve the medical research literature. PLoS Med. 2015;12(9):e1001864.

6. World Association of Medical Editors. Policies and Resources. http://www. wame.org/policies-and-resources. Accessed 4 November 2014.

7. Committee on Publication Ethics. http://publicationethics.org/. Accessed 4 November 2014.

8. Journalology Blog. http://journalology.blogspot.ca/. Accessed 4 November 2014.

9. PSP Consulting. Editing medical journals - short course. http://www. pspconsulting.org/medical-short.shtml. Accessed 4 November 2014.

10. Council of Science Editors. Short Courses. http://www.resourcenter.net/Scripts/ 4Disapi07.dll/4DCGl/events/2015/516-ShortCourses.html?Action=Conference_ Detail\&ConflD W=516\&ConflD W=516. Accessed 27 August 2015.

11. Frank JR, Snell LS, Cate OT, Holmboe ES, Carraccio C, Swing SR, et al. Competency-based medical education: theory to practice. Med Teach. 2010;32(8):638-45.

12. uO Research. https://www.ruor.uottawa.ca/handle/10393/32305?mode=full. Accessed 27 August 2015.

13. Arksey H, O'Malley L. Scoping studies: towards a methodological framework. Int J Soc Res Methodol. 2005;8(1):19-32.

14. Levac D, Colquhoun H, O'Brien KK. Scoping studies: advancing the methodology. Implement Sci. 2010;5(1):1-9.

15. Sampson M, McGowan J, Cobo E, Grimshaw J, Moher D, Lefebvre C. An evidence-based practice guideline for the peer review of electronic search strategies. J Clin Epidemiol. 2009;62(9):944-52.

16. Peer Review Congress. http://www.peerreviewcongress.org/index.html. Accessed 8 November 2014.

17. Galipeau J, Moher D, Campbell C, Hendry P, Cameron DW, Palepu A, et al. A systematic review highlights a knowledge gap regarding the effectiveness of health-related training programs in journalology. J Clin Epidemiol. 2015;68(3):257-65.

18. Galipeau J, Moher D. Repository of Ongoing Training Opportunities in Journalology. http://www.wame.org/about/repository-of-ongoing-trainingopportunities. Accessed 27 August 2015.

19. US National Library of Medicine. Fact Sheet: MEDLINE Journal Selection. https:// www.nlm.nih.gov/pubs/factsheets/jsel.html. Accessed 4 November 2014.

20. Reuters T. Reference Manager. New York: Thomson Reuters; 2038.

21. Khangura S, Konnyu K, Cushman R, Grimshaw J, Moher D. Evidence summaries: the evolution of a rapid review approach. Syst Rev. 2012;1(1):1-9.

22. Smart $P$, Maisonneuve $H$, Polderman AKS. EASE Science editors' handbook (2nd Ed). EASE, the European Association of Science Editors, 2013. Available from http://www.ease.org.uk/handbook/index.shtml. Accessed 4 Nov 2014.

23. Marusic A, Katavic V, Marusic M. Role of editors and journals in detecting and preventing scientific misconduct: strengths, weaknesses, opportunities, and threats. Med Law. 2007;26(3):545.

\section{Submit your next manuscript to BioMed Central and we will help you at every step:}

- We accept pre-submission inquiries

- Our selector tool helps you to find the most relevant journal

- We provide round the clock customer support

- Convenient online submission

- Thorough peer review

- Inclusion in PubMed and all major indexing services

- Maximum visibility for your research

Submit your manuscript at www.biomedcentral.com/submit

) Biomed Central 